OPEN ACCESS

Edited by:

Yujing $L i$,

Emory University, United States

Reviewed by:

Peter lgaz,

Semmelweis University, Hungary Roberto Gherzi,

University of California, San Diego,

United States

*Correspondence:

Francesca Fanin

francesca.fanini@irst.emr.it

Specialty section:

This article was submitted to

$R N A$,

a section of the journal

Frontiers in Genetics

Received: 18 October 2018

Accepted: 26 February 2019

Published: 19 March 2019

Citation:

Bandini E and Fanini F (2019) MicroRNAs and Androgen Receptor:

Emerging Players in Breast Cancer.

Front. Genet. 10:203.

doi: 10.3389/fgene.2019.00203

\title{
MicroRNAs and Androgen Receptor: Emerging Players in Breast Cancer
}

\section{Erika Bandini and Francesca Fanini*}

Biosciences Laboratory, Department of Clinical and Experimental Oncology and Hematology, Istituto di Ricovero e Cura a Carattere Scientifico, Istituto Scientifico Romagnolo per lo Studio e la Cura dei Tumori (I.R.S.T.) S.r.l. IRCCS, Meldola, Italy

Breast cancer $(\mathrm{BC})$ is the most common cause of cancer among women, with a high incidence rate occurrence every year worldwide despite advances in its management. $\mathrm{BC}$ is characterized by a spectrum of subtypes which respond differently to treatments due to their biological features, representing the main issue in the control of this type of malignancy. Androgen receptor (AR) is emerging as a target to investigate among hormone receptors, since it seems to play a role at various stages of development of specific BC subsets. For this reason, in recent years AR has become very important in the clinical practice, although its role remains controversial. A number of studies have proposed a correlation between microRNAs (miRNAs), a class of gene expression modulators, and AR in prostate cancer (PC), but there are still few evidences about the relationship between miRNAs and $A R$ in $B C$. The purpose of this review is to present a state of the art scenario with consideration to the most recent discoveries about miRNAs involved in the AR associated pathogenesis of $\mathrm{BC}$, in order to provide new insights into the role of miRNAs as key drivers in the modulation of $A R$, and possible actors in the development and progression of BC. Moreover, we consider findings about involvement of $A R$ signaling in all stages of $B C$, highlighting its association with different subsets of breast carcinomas and with pre- and postmenopausal state of patients.

Keywords: microRNAs, androgens, receptor, breast, cancer

\section{INTRODUCTION}

Breast cancer (BC) is the most common cause of cancer among women and in 2018 in the United States 266,120 new cases and 40,920 deaths have been estimated (Siegel et al., 2018). Despite advances in the management of the disease, a high incidence rate occurs every year worldwide as a consequence of several factors such as socioeconomic differences in the population (Lukong et al., 2017; Dean et al., 2018), ethnicity (DeSantis et al., 2017; Foy et al., 2018), dietary habits (Tabung et al., 2016; Nattenmüller et al., 2018), and disparities in screening programs (Miglioretti et al., 2015). The study of $B C$ has highlighted a substantial tissue heterogeneity, showing several molecular profiles each with distinct clinical and biological features (Perou et al., 2000) which make this tumor differently responsive to treatments, and adverse in its management. In the last years, molecular profiling by gene expression and transcriptional studies has provided an important tool to classify BCs into four well-established subtypes: Luminal A, Luminal B, Basal-like, and

Abbreviations: AR, androgen receptor; $\mathrm{BC}$, breast cancer; DFS, disease-free survival; DHT, dihydrotestosterone; E2, $\beta$-estradiol; ER, estrogen receptor; miRNAs, microRNAs; MA, molecular apocrine; OS, overall survival; PC, prostate cancer; PGR, progesterone receptor; RFS, relapse-free survival; TNBC, triple negative breast cancer. 
human epidermal growth factor receptor 2 (Her2)-enriched (Parker et al., 2009). Among Basal like group, TNBC represents a heterogeneous category of cancer whose immunohistochemical classification lacks of ER, PGR, and HER2 protein expression. Up to day, several studies have been conducted in order to better identify molecular-based therapies. Integrated molecular analyses have significantly enhanced the knowledge about genomic drivers of the most common $\mathrm{BC}$ subtypes, giving prominence to the discovery of novel subtype-specific targets that can be exploited in the future especially for the treatment of TNBCs (Koboldt et al., 2012; Burstein et al., 2015). Lehmann et al. analyzed 587 TNBC cases and identified 6 TNBC subtypes displaying unique gene expression profile: two basal-like (BL1 and BL2), an immunomodulatory (IM), a mesenchymal (M), a mesenchymal stem-like (MSL) and a Luminal Androgen Receptor subtype (LAR), composed of AR driven tumors, and that has been suggested to be correlated to the previously identified by Farmer et al. "Molecular Apocrine" subtype (MA) (Farmer et al., 2005; Lehmann et al., 2011; Lehmann-Che et al., 2013). Among these subtypes, LAR type was found to be associated with older patient age, apocrine histologic features, low density of stromal tumorinfiltrating lymphocytes (TIL), and low Ki-67 labeling index (Kim et al., 2018). Sex steroid hormone receptors, ER and PGR, have always played a leading role in the development and progression of BC; however, in the last years, AR has emerged as a prominent player to focus attention on. In terms of therapeutic options, AR may provide a further strategy to counteract breast malignancy, especially in patients with ER negative (ER-) tumors that do not benefit from endocrine or Her2 targeted treatments. In the last decades several small molecules have been identified as critical regulators of transcription and translation of proteins involved in tumorigenesis, and among them miRNAs are the most studied. They belong to a broad family of small noncoding RNAs, and they deserve great attention since they can modify the expression of tumor suppressor genes or oncogenes, affecting signaling pathways of cancer cells. The function of miRNAs in BC has been deeply explored, with the first miRNA signature reported by Iorio et al., and followed by a plethora of studies that have determined a functional role of miRNAs in the disease (Iorio et al., 2005). Anyway, little is known about the emerging dysregulation mechanisms of miRNAs in the context of hormonal signaling, especially for androgens. In this review, we present a state of the art scenario about the role of AR in $\mathrm{BC}$, highlighting the main issues about this "player" that is very debating especially for what concerns its function in different subsets of breast carcinomas. Moreover, we focus on the most recent discoveries about miRNAs involved in the AR associated pathogenesis of BC, since so far this topic has been considered almost exclusively in PC.

\section{THE ROLE OF ANDROGEN RECEPTOR IN BREAST CANCER}

Androgen receptor is a member of the family of steroid nuclear receptors which mediates the biological effects of androgens. It is well established that $\mathrm{AR}$ is considered an oncogenic driver at all stages of PC, but its role in BC remains controversial. In fact, expression of AR splice variants (ARVs) has been elucidated in $\mathrm{PC}$, but only recently the presence of multiple known and novel ARV transcripts has been demonstrated in a panel of BC cell lines and human tissues: AR-V1, -V3, -V4, -V7, and -V9 (Hu et al., 2014). In particular, AR-V7 was observed to be constitutively active and involved in androgen deprivation resistance in more than $50 \%$ of BC cases (Hickey et al., 2015). Whereas AR and ER- $\alpha$ have a quite similar structure and are co-expressed by many BCs, the role of AR may be different depending on the levels of both hormone receptors in the tumor environment. This becomes important in the evaluation of clinical practice, as in pre-clinical models of BC AR was able either to stimulate or inhibit cell proliferation (Macedo et al., 2006; Lin et al., 2009).

In the last years several studies have focused on the role of $\mathrm{AR}$ in ER- $\alpha$ positive (ER+) BCs, since there would seem to be a correlation between its expression grade and some clinical advantages. In fact high levels of AR are associated to reduced lymph node involvement, better DFS, RFS, and OS, response to endocrine therapies and chemotherapy, lower tumor grade, Ki67 expression, smaller tumor size and less necrosis, suggesting for $\mathrm{AR}$ a possible role as a tumor-suppressor in malignant breast epithelial cells (Peters et al., 2009; Castellano et al., 2010; VeraBadillo et al., 2014). Rangel et al. investigated the prognostic impact of $\mathrm{AR} / \mathrm{ER}$ ratio in $402 \mathrm{ER}+\mathrm{BC}$ patients, showing its inverse relation with aggressiveness of biological features and worse prognosis (Rangel et al., 2018b). Similarly, Basile et al. reported that a high $\mathrm{AR} / \mathrm{ER}$ ratio seems to be detrimental in BC treated with endocrine therapy (Basile et al., 2017), while in 2 validated $\mathrm{BC}$ cohorts, $\mathrm{ER}+$ patients with $\mathrm{AR}$ positivity $\geq 78 \%$ had the best survival, and among them those with a ratio of AR: $\mathrm{ER} \alpha>0.87$ exhibited the best outcomes (Ricciardelli et al., 2018). In a study involving $479 \mathrm{BC}$ women, it has been evidenced that in ER+ patients the expression of forkhead box A1 (FOXA1), a pioneer factor which helps the recruitment of ER and AR to their response elements on the genome, was directly correlated to the presence of AR and to better outcome, providing additional knowledge about recurrence (Rangel et al., 2018a). Also Park et al. confirmed that ER+ patients with low expressed AR and FOXA1 tumors were significantly correlated to worse RFS (Park et al., 2017). Moreover, recent data showed that over $90 \%$ of metastasis from luminal tumors preserved FOXA1 expression (Ross-Innes et al., 2012), and the concomitant expression of AR and FOXA1 in metastatic lesions may promote the luminal to MA transition. In TNBCs, $\mathrm{AR}$ is expressed in 10-43\% of cases but its prognostic value remains still unclear. Actually, larger cohort numbers should be needed to determine a role for AR in this peculiar subtype. In some studies involving TNBC cases, the presence of AR appeared correlated to an increase in overall mortality, lymph node metastasis and higher tumor stage (Hu et al., 2011; McGhan et al., 2014). Conversely, another group demonstrated that androgen pathways are associated with reduced aggression TNBC, and that AR loss may have a role in the progression of the tumor (McNamara et al., 2014). A meta-analysis involving 13 studies with 2826 TNBC cases, suggested a potential role of AR in a lower risk of recurrence highlighting that AR positive women showed prolonged DFS (Wang et al., 2016). After analysis of 135 
invasive TNBC cases, AR and epidermal growth factor receptor (EGFR) expression was evaluated in order to stratify TNBCs into three risk groups: low risk (AR+ EGFR-) characterized by better prognosis and beneficial from anti-androgen therapies; high risk (AR- EGFR+) with worst prognosis, but better responsiveness to chemotherapy; and intermediate-risk (AR+ EGFR+, AR-, EGFR-) (Astvatsaturyan et al., 2018).

Molecular apocrine subtype has been studied in vitro using $\mathrm{BC}$ cell lines whose growth was promoted by AR expression. Robinson et al. demonstrated that in the absence of ER- $\alpha$ more than a half of AR binding events showed an analogous pattern to that of ER- $\alpha$ in ER + cells, promoting the expression of ER target genes, and suggesting a role of AR as a ER- $\alpha$ mimic (Robinson et al., 2011). Anyway, the biological interaction between ER- $\alpha$ and AR still needs to be clarified. Curiously, in a transcriptomic study involving male $\mathrm{BC}$, chromatin binding landscape of $E R$ in relation to steroid hormone receptors including $A R$, was determined. Results showed that AR pathway was the only hormonal signaling more associated with the $E R-\alpha$ binding genes, confirming that genomic functions of $E R-\alpha$ and $A R$ in BC are largely overlapping (Severson et al., 2018). For what concerns HER2-enriched BC subtype, it has been found strongly related to MA and studies have suggested a strong evidence of the proliferative role of AR (Ni et al., 2011; Chia et al., 2015). Lehmann-Che et al. tried to characterize MA tumors and found that they were all defined ER-, AR+, FOXA1+, with an overexpression of HER2 or prolactin induced protein (GCDFP15), useful for discriminating MA from basal-like (BL) in the context of ER- tumors. This distinction can be useful to include MA patients in specific "AR pathway" trials, being this subtype rather aggressive (Lehmann-Che et al., 2013). There are evidences that AR can promote ERK activation up-regulating HER2 gene transcription, therefore contributing to the growth of Her2+ BC (Naderi and Hughes-Davies, 2008; Chia et al., 2011). More recently, the functional role of $\mathrm{AR}$ was investigated by silencing assays and a reduction in the growth of $\mathrm{Her} 2+\mathrm{BC}$ cells HCC1954 and SKBr3 was observed, also after treatment with the androgen antagonist Enzalutamide, highlighting a function of AR in promoting the growth of Her2+ BC cells (He et al., 2017). Daemen and Manning explored HER2 amplification in 3155 breast tumors and found that the HER2-enriched (HER2E) subtype had a distinct transcriptional landscape independent of HER2-amplificated (HER2A) that reflected and confirmed how AR signaling can replace ER-driven tumorigenesis (Daemen and Manning, 2018). In a study involving 1297 primary tumors and 336 paired axillary lymph node metastases, Kraby et al. found a highest proportion of AR positivity in the Luminal B subtype while the lowest was observed in the basal phenotype. Interestingly, in 60/72 cases a changeover from AR- primary tumor to AR+ lymph node metastasis occured. Moreover, in primary tumors AR expression was an independent and favorable prognostic marker, particularly in the Luminal A subtype, and in grade 3 tumors (Kraby et al., 2018). All these observations underline the need for a more detailed classification of tumor samples aimed at a more targeted and personalized treatment of patients. The role of AR in BC subtypes is resumed in Table 1.

$\mathrm{AR}$ is expressed in all stages of $\mathrm{BC}$ (in situ, primary and metastatic). In fact, it is estimated that up to $90 \%$ of primary $\mathrm{BC}$ and up to $75 \%$ of metastatic lesions expressed AR (Hickey et al., 2012), as well as in the $50-80 \%$ of invasive BCs and in the $85 \%$ of ductal carcinoma in situ (DCIS) (Lim et al., 2014), although among the BC subtypes the frequency appears variable. Nevertheless, its role in breast carcinogenesis remains a debated topic as its contribution to the different tumor stages development and progression still needs to be clarified. Feng et al. reported the involvement of DHT in the initiation of epithelial-to-mesenchymal transition (EMT) of BC cells in an AR-dependent but ER-independent manner, indicating the role of androgens in cancer invasion and metastasis (Feng et al., 2017), Schrijver et al. investigated receptor conversion in 91 effusion metastasis, pleural and peritoneal, of 69 patients by immunohistochemistry and in situ hybridization. AR receptor status changed from positive in the primary tumor to negative in the effusion metastases or vice versa in $46-51 \%$ of cases, and

TABLE 1 | The role of AR in BC subtypes.

\begin{tabular}{ll}
\hline Tumor subtype & AR role \\
\hline ER+ & $\begin{array}{l}\text { Tumor-suppressor: associated with low } \\
\text { aggressiveness and better outcome }\end{array}$ \\
& \\
TNBC & $\begin{array}{l}\text { Tumor-suppressor: associated with low } \\
\text { aggressiveness and progression, and better } \\
\text { outcome } \\
\text { Oncogenic: associated with aggressiveness } \\
\text { and worse outcome }\end{array}$ \\
TNBC AR+/EGFR- TNBC AR+/EGFR+ & Associated with better prognosis \\
TNBC AR-/EGFR- TNBC AR-/EGFR+ & Assoup with intermediate risk \\
MA ER- & ER mimic \\
HER2-enriched & Proliferative
\end{tabular}

Luminal A primary tumors
Favorable prognostic marker

\section{Reference}

Peters et al., 2009; Castellano et al., 2010; Vera-Badillo et al., 2014; Basile et al., 2017; Kim et al., 2017; Rangel et al., 2018a,b; Ricciardelli et al., 2018 McNamara et al., 2014; Wang et al., 2016

Hu et al., 2011; McGhan et al., 2014

Astvatsaturyan et al., 2018

Robinson et al., 2011; Severson et al., 2018

Naderi and Hughes-Davies, 2008; Ni et al., 2011; Chia et al., 2015; He et al., 2017; Daemen and Manning, 2018

Kraby et al., 2018 
this was more often associated in patients previously treated with ET (Schrijver et al., 2017). This new finding could be relevant for investigating AR-targeted therapies in ER- and endocrine resistant $\mathrm{BC}$. RNA sequencing was performed to investigate CTCs isolated from blood samples of patients with metastatic $\mathrm{ER}+\mathrm{BC}$, and a comparison between cases with progression in bone vs. visceral organs was made. Results showed that the most activated pathway in CTCs from bone was that of AR, especially involving splice variant AR-V7. Curiously, AR expression within CTCs was associated with the duration of treatment with aromatase inhibitors (AIs), proposing a possible mechanism in the contribution of acquired resistance to ET, and underlying the role of $\mathrm{AR}$ in $\mathrm{BC}$ bone metastasis together with the therapeutic option of its targeting in patients with metastatic setting (Aceto et al., 2018). Usually, the maintenance of the balance between DHT, the most potent endogenous AR ligand derived from testosterone (Labrie et al., 2003; Gao et al., 2005), and E2 ensures the physiological response of the breast tissue, including $\mathrm{BC}$ tissue, depending on the hormonal needs and the menopausal status. In fact, the circulating androgens concentration varies in woman in relation to pre and postmenopause state (Giovannelli et al., 2018). Whereas after menopause circulating level of E2 decrease dramatically up to 10 -fold, androgens begin to acquire an important function (Rothman et al., 2011). Several studies have tried to analyze the correlation between circulating androgens and $\mathrm{BC}$ growth since this relationship remains unclear, although up to now a high serum testosterone level has been associated with an increased risk in postmenopausal women. It follows that an additional complication in understanding the role of $\mathrm{AR}$ is to be attributed to the menopausal state of patients, which seems to be a more significant variable than age. It would be important to distinguish between the intratumoral estrogen or androgen production, and to take into consideration the balance between these different sex hormones. The most of breast tumors are estrogen-dependent and are characterized by a high expression of ER that could interfere with the activity of AR and vice versa. Premenopausal patients $\mathrm{BC}$ tissues are characterized by higher production of estrogen, and in these individuals ovary is the main source of E2. Otherwise, in postmenopausal state estrogens derived from circulating adrenal androgens, such as androstenedione, and in these patients $\mathrm{BC}$ tissues presents lower levels of E2 and higher androgen levels (Takagi et al., 2018). How hormonal changes influence cancer development is still a discussed issue. Curiously, data showed that in recent decades incidence rates of advanced BC have increased for premenopausal women (Fahlén et al., 2018).

\section{THE INTERACTION BETWEEN miRNAS AND ANDROGEN RECEPTOR IN BREAST CANCER}

MicroRNAs are the most explored non-coding RNAs, and give rise to a large family of short (19-24 nucleotides) single-strand RNAs which take part in a variety of biological processes, such as cell proliferation, death, differentiation, and stress response (Bartel, 2004; Kozomara and Griffiths-Jones, 2014). They operate recognizing a 2-7 nucleotides "seed-region" in the target mRNA, which can be localized in the $3^{\prime}$-UTR (Lewis et al., 2005), in the $5^{\prime}$-UTR (Lytle et al., 2007), or in the coding region (Forman et al., 2008). Their regulatory function on gene expression is performed through the control of translation of the mRNA target, which can result in downregulation but also in upregulation of the encoded protein (Ambros, 2004; Vasudevan et al., 2007). A decisive turning point was given by Fabbri et al., who highlighted for the first time the ability of miRNAs secreted by tumor-derived exosomes (TEX) to act as paracrine agonists of a specific receptor family suggesting an involvement in the tumor microenvironment interaction and a new possible target for cancer treatment (Fabbri et al., 2012). On this trail, other groups started to analyze the implication of miRs in tumor communication, growth and spread, and recently it has been demonstrated how breast-cancer TEX are able to carry precursor miRNAs (pre-miRNAs) complexed with Dicer, TRBP and AGO2 proteins displaying a cell-independent capacity to process premiRNAs into mature form, contributing to the comprehension of a cell-autonomous process occurring in exosomes when secreted into the extracellular space (Melo et al., 2014).

A number of studies have proposed a correlation between miRNAs and AR in PC (Shi et al., 2007; Epis et al., 2009; Ribas et al., 2009; Cao et al., 2010; Nadiminty et al., 2012), but there are still few evidences about the possible role of miRNAs in regulating $\mathrm{AR}$ expression in $\mathrm{BC}$. For the first time, Nakano et al., through miRNAs Polymerase Chain reaction (PCR) Arrays, identified miR-363 as an androgen-inducible miRNA. In MCF-7 $\mathrm{BC}$ cells they highlighted a possible androgens-related feedback loop involving the gene IQWD1 (IQ motif and WD repeats1) and miR-363: under low androgens levels IQWD1 was downregulated by miR-363, but this negative modulation did not occurred after DHT administration (Figure 1A). Interestingly, IQWD1 has a role in protecting AR proteins from degradation via proteasome (Nakano et al., 2013). In AR+/ER- models, androgens seemed to mediate a negative correlation between miR-let-7a and the expression of its target oncogenes CMYC and KRAS. In particular, in the MA MDA-MB 453 and in the TNBC MDA-MB 231 cell lines treated with DHT a significant increase in let-7a expression was observed together with a decrease of CMYC and KRAS (Figure 1B). Similarly, in BC tissues the negative correlation was confirmed by IHC, highlighting a new androgen-induced AR activating signal pathway that directly upregulates let-7a and negatively regulates CMYC and KRAS, inhibiting proliferation of AR+/ER - cells (Lyu et al., 2014). Results about the tumor suppressive role of let-7a were confirmed also in AR+/ER+ BC cells, where DHT stimulation led to an AR translocation to the nucleus with transcriptional upregulation of let-7a, decreased cell proliferation, self-renewal capacities, invasion and migration (Zhang et al., 2018). Moreover, in order to deepen the effects of let-7a/AR pathway on breast tumor-initiating cells, Zhang et al. examined the expression of $\mathrm{AR}$, let- $7 \mathrm{a}$ and $\mathrm{CD} 44^{+} / \mathrm{CD} 24^{-/ \text {low }}$ in invasive $\mathrm{BC}$ tissues. $\mathrm{AR}$ was significantly correlated to let-7a and CD $44^{+} / \mathrm{CD} 24^{-/ \text {low }}$, highlighting that patients expressing $\mathrm{AR}$ and let-7a could have a better outcome, unlike those with a $\mathrm{CD} 44^{+} / \mathrm{CD} 24^{-/ \text {low }}$ phenotype which showed a worse prognosis. These findings put 




FIGURE 1 | Androgenic-inducible miRNAs involved in the process of BC progression. (A) In Luminal A BC cells, DHT treatment induces an androgen-related miRNA-mRNA pathway, involving miR-363 and its possible target gene IQWD1. In the presence of high levels of androgens, a IQWD1 feed-forward regulation activates its own AR-mediated expression (Chen et al., 2007), and miR-363 significantly increased. Under relatively low level of DHT, IQWD1 is negatively regulated by miR-363. (B) In MA and TNBC cells, the DHT administration results in an androgen-induced AR activating signal pathway which upregulates let-7 expression and negatively regulates CMYC and KRAS that are targets of let-7. (C) In TNBC cells, the IncRNA ARNILA is negatively regulated by AR after DHT treatment, causing a decreased adsorption of miR-204 which in turn inhibits Sox4 expression, a gene known to promote EMT. (D) In TNBC cells, DHT induces upregulation of miR-328-3p with concomitantly decrease of its target CD44, diminishing EMT, migration and adhesion.

in evidence that DHT-induced AR activation plays a critical role in $\mathrm{BC}$, and that $\mathrm{AR} / \mathrm{let}-7 \mathrm{a}$ signaling could be exploited as a new optional therapeutic target (Zhang et al., 2018). Another study evidenced the interaction between AR and miRNAs in controlling BC cells behavior. Three BC cell lines (Luminals and MA subtypes) were screened for 84 miRNAs showing each of 


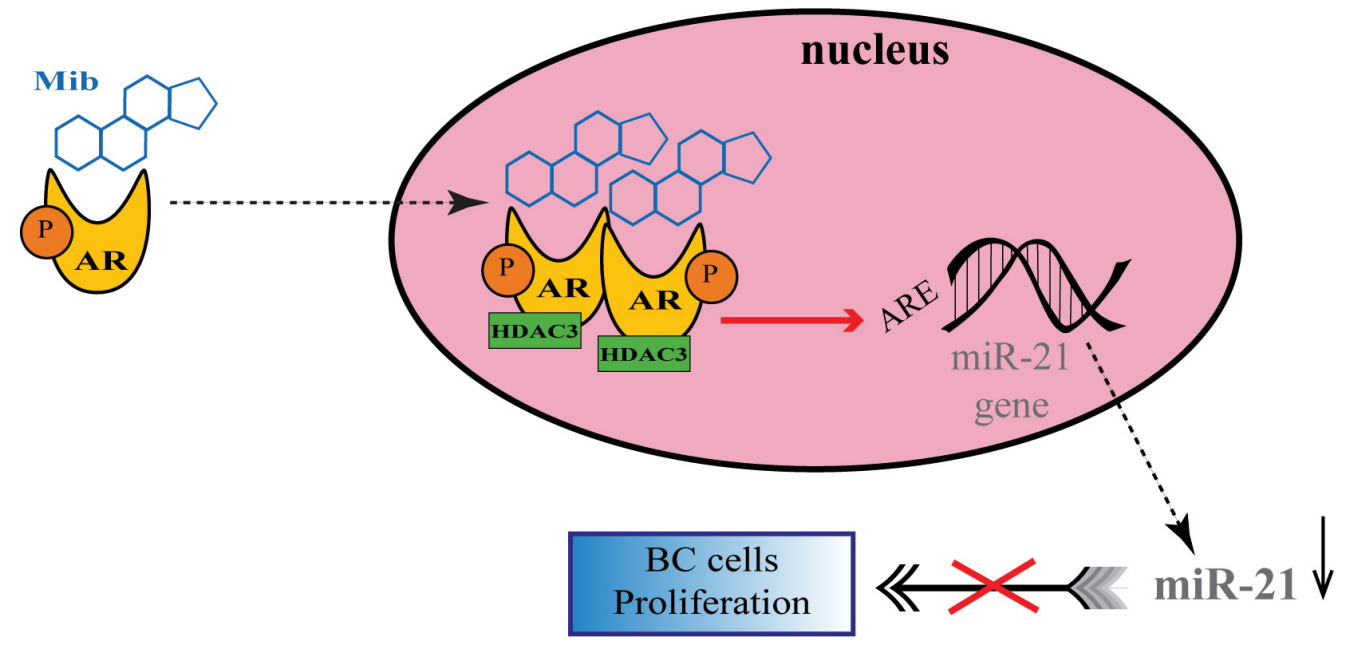

FIGURE 2 | Regulation of onco-miR-21 by AR transcriptional inhibition in BC. Upon miboleron (Mib) binding the AR undergoes a conformational change and translocates to the nucleus where it works as transcriptional inhibitor of onco-miR-21 expression, after recruitment of the co-factor HDAC3. The negative modulation of the onco-mir-21 results in a reduction of $\mathrm{BC}$ cells proliferation.

them a distinct basal miRNAs expression profile. High level of let-7a and -7b found in MA-MDA-453 appeared to be distinctive for MA subtype, whereas miR-205 seemed to represent a marker in the luminal T47D and MCF-7 cells. Furthermore, treatment with the AR agonist CI-4AS-1 led to alterations in the expression profile of other micro-RNAs, such as miR-100 and miR-125 which were found significantly downregulated simultaneously with the increase and extracellular release of metalloprotease-13 (MMP13). Interestingly, the transfection of miR-100 and $-125 \mathrm{~b}$ abrogated the induction of MMP13, suggesting a correlation between these micro-RNAs and AR in the control of BC growth (Ahram et al., 2017). In TNBC, the gene SRY-box 4 (Sox4) is known to promote EMT, thereby progression, invasion and metastasis, and is found abnormally overexpressed. Yang et al. identified an AR negatively induced long non-coding RNA (lncRNA) ARNILA that correlated to poor PFS, tightly connected to $\mathrm{AR}$ and able to sequester miR-204, in turn facilitating the expression of its target Sox4. Particularly in AR+ carcinomas, ARNILA is suppressed by the action of DHT and AR, resulting in the decreased adsorption of miR-204 thus favoring Sox 4 expression inhibition. On the other hand, in AR- tumors, the action of ARNILA leads to Sox 4 expression by increasing the sequestration of miR-204, leading to the induction of EMT and metastatic propagation (Figure 1C). All together these findings spread light to the discovery of new lncRNA/miRNA/AR mechanisms correlated with poor clinical outcome by regulating EMT, migration, and invasion in TNBC (Yang et al., 2018). Again in TNBC, investigating the modulation of miRNAs after treatment with DHT a group reported miR-328-3p as the most upregulated. Concomitantly, CD44 target of miR-328$3 \mathrm{p}$, decreased, diminishing cell adhesion, migration and EMT, and this result was confirmed also after miR-328-3p mimic transfection (Figure 1D) (Al-Othman et al., 2018). In another study, a total of 153 miRNAs were found to be differentially expressed in AR+ vs. AR- cell lines. The authors identified
miR-143, $-145,-31,-30 c,-30 b-3 p, 199 a$, and -181 as significantly downregulated in AR+ cells, while miR-933 and -5793 appeared as the most upregulated, suggesting a role for these miRNAs in the regulation of AR in BC (Shi et al., 2017). Again, the interaction between miR-30a and AR was explored, and miR30a role was investigated in $\mathrm{ER}-, \mathrm{PR}-, \mathrm{AR}+, \mathrm{MDA}-\mathrm{MB}-453$ BC cells. After DHT treatment, which activates Androgeninduced AR signal, a miRNAs profile was identified by miRNAs array, showing a downregulated expression of miR-30a, b and $c$ (among which the most downregulated was miR-30a), and an upregulated expression of AR. Interestingly, in the AR mRNA $3^{\prime}$-untranslated region resides a bioinformatic putative miR-30a, $\mathrm{b}$ and $\mathrm{c}$ binding site confirming $\mathrm{AR}$ as a direct target of miR30a. Nevertheless, AR does not bind miR-30a promoter region which could be downregulated through other AR-induced cell signaling pathways. This study identified a positive feedback mechanism of regulation which could be explained by two effects. First, the activation of AR expression and AR-induced signal downregulates mir-30a expression that in turn promotes AR availability. Second, the downregulation of mir-30a expression has a negative effect on the inhibition of cell growth induced by itself, being miR-30a a cancer suppressor gene (Lyu et al., 2017). Interestingly, Casaburi et al. reported that androgens can reduce $\mathrm{BC}$ cells proliferation by negative modulation of the onco-miR-21. By treatment with synthetic androgen miboleron (Mib) and Chromatin immune-precipitation (ChIP) analysis, they provided evidence that activated AR works as a transcriptional inhibitor of miR-21 expression. In particular, AR was able to bind the proximal promoter of miR-21 in a specific ARE sequence, involving the recruitment of HDAC3 as cofactor in the AR-mediated transcriptional repression (Figure 2). This hypothesis was also supported by a significant reduction of PolII binding in Mib treated extracts, providing further evidence about the protective role of androgens in BC cells (Casaburi et al., 2016). 


\section{DISCUSSION AND FUTURE HORIZONS}

Many studies support the idea that BC is a heterogeneous pathology and this consideration is mainly motivated by the existence of different subtypes classified on the basis of hormone receptor expression. About $70-80 \%$ of BC express considerable level of ER and are estrogen-dependent (Takagi et al., 2018), but, as well, approximately $70-90 \%$ of them express AR, and close to $75 \%$ are considered to express both AR and ER (VeraBadillo et al., 2014) suggesting a role of androgen hormones in the pathogenesis of BC. Although up today the association between levels of circulating androgens and $\mathrm{BC}$ risk is still under discussion, several studies identified $\mathrm{AR}$ as a marker of favorable prognosis and have demonstrated the anti-proliferative effects of androgens in BC cells (Andò et al., 2002; Lanzino et al., 2010; Takagi et al., 2010). Definitely, in this moment the scientific community can only state that the AR positivity makes more intricate the $\mathrm{BC}$ molecular outlook. It has been suggested that circulating androgens may have a role both as independent molecules and as substrate for estrogen synthesis, but limited to $\mathrm{AR}+/ \mathrm{ER}+\mathrm{BC}$ since in $\mathrm{AR}+/ \mathrm{ER}-\mathrm{BC}$ they may act in a more homogenous way (Giovannelli et al., 2018). On the basis of different androgens effects on BC, several approaches having AR as a target have been evaluated, including AR agonists and antagonists.

Since the findings that miRNAs play a role in carcinogenesis and are deregulated in several types of tumor, they have obtained a lot of interest about their potential use as therapeutic agents in chemotherapy. Furthermore, the supposing of the existence of

\section{REFERENCES}

Aceto, N., Bardia, A., Wittner, B. S., Donaldson, M. C., O’Keefe, R., Engstrom, A., et al. (2018). AR expression in breast cancer CTCs associates with bone metastases. Mol. Cancer Res. 16, 720-727. doi: 10.1158/1541-7786.MCR-170480

Ahram, M., Mustafa, E., Zaza, R., Abu Hammad, S., Alhudhud, M., Bawadi, R., et al. (2017). Differential expression and androgen regulation of microRNAs and metalloprotease 13 in breast cancer cells. Cell Biol. Int. 41, 1345-1355. doi: $10.1002 /$ cbin. 10841

Al-Othman, N., Hammad, H., and Ahram, M. (2018). Dihydrotestosterone regulates expression of CD44 via miR-328-3p in triple-negative breast cancer cells. Gene 675, 128-135. doi: 10.1016/j.gene.2018.06.094

Ambros, V. (2004). The functions of animal microRNAs. Nature 431, 350-355. doi: 10.1038/nature02871

Andò, S., De Amicis, F., Rago, V., Carpino, A., Maggiolini, M., Panno, M. L., et al. (2002). Breast cancer: from estrogen to androgen receptor. Mol. Cell. Endocrinol. 193, 121-128. doi: 10.1016/S0303-7207(02)00105-3

Astvatsaturyan, K., Yue, Y., Walts, A. E., and Bose, S. (2018). Androgen receptor positive triple negative breast cancer: clinicopathologic, prognostic, and predictive features. PLoS One 13:e0197827. doi: 10.1371/journal.pone. 0197827

Bartel, D. P. (2004). MicroRNAs: genomics, biogenesis, mechanism, and function. Cell 116, 281-297. doi: 10.1016/S0092-8674(04)00045-5

Basile, D., Cinausero, M., Iacono, D., Pelizzari, G., Bonotto, M., Vitale, M. G., et al. (2017). Androgen receptor in estrogen receptor positive breast cancer: beyond expression. Cancer Treat. Rev. 61, 15-22. doi: 10.1016/j.ctrv.2017. 09.006

Burstein, M. D., Tsimelzon, A., Poage, G. M., Covington, K. R., Contreras, A., Fuqua, S. A. W., et al. (2015). Comprehensive genomic analysis identifies novel a specific uptake can help the purpose to customize miRNAs as therapeutics alone or, more likely, in combination with today's anti-cancer therapies. Surely more stress should be placed on understanding the balance between AR and ER in relation to the different subtypes, which gives rise to main questions regarding a different response to endocrine therapies in BC. For instance, the interesting positive feedback mechanism identified by Lyu et al. between AR and miR-30a could be a starting point for further studies about the role of miRNAs as a therapeutic predictive markers, besides the identification of other miRs that are able to target $\mathrm{AR}$, or molecules involved in the AR pathway, can certainly help to find more answers about this interaction (Lyu et al., 2017). Also, not to be underestimated is the recent intriguing branch of miRceptor which fits very well in the context of $\mathrm{BC}$ as a hormone-dependent tumor, and which is linked to broader themes such as the study of the tumor microenvironment. Consequently, it is reasonable to foresee how the interaction between miRNAs and AR in BC can become in the future an extensively investigated field, in order to increase the treatment chances and try to get much closer to $\mathrm{BC}$ personalized therapies.

\section{AUTHOR CONTRIBUTIONS}

EB wrote the first draft of the manuscript. FF contributed to the writing of the manuscript. FF and $\mathrm{EB}$ drew figures and tables. Both authors critically reviewed the manuscript and approved the final version of the manuscript.

subtypes and targets of triple-negative breast cancer. Clin. Cancer Res. 21, 1688-1698. doi: 10.1158/1078-0432.CCR-14-0432

Cao, P., Deng, Z., Wan, M., Huang, W., Cramer, S. D., Xu, J., et al. (2010). MicroRNA-101 negatively regulates Ezh2 and its expression is modulated by androgen receptor and HIF-1 $\alpha /$ HIF-1 $\beta$. Mol. Cancer 9:108. doi: 10.1186/14764598-9-108

Casaburi, I., Cesario, G. M., Donà, A., Rizza, P., Aquila, S., Avena, P., et al. (2016). Androgens downregulate miR-21 expression in breast cancer cells underlining the protective role of androgen receptor. Oncotarget 7, 12651-12661. doi: 10. 18632 /oncotarget.7207

Castellano, I., Allia, E., Accortanzo, V., Vandone, A. M., Chiusa, L., Arisio, R., et al. (2010). Androgen receptor expression is a significant prognostic factor in estrogen receptor positive breast cancers. Breast Cancer Res. Treat. 124, 607-617. doi: 10.1007/s10549-010-0761-y

Chen, P.-H., Tsao, Y.-P., Wang, C.-C., and Chen, S.-L. (2007). Nuclear receptor interaction protein, a coactivator of androgen receptors (AR), is regulated by $\mathrm{AR}$ and $\mathrm{Sp} 1$ to feed forward and activate its own gene expression through $\mathrm{AR}$ protein stability. Nucleic Acids Res. 36, 51-66. doi: 10.1093/nar/gkm942

Chia, K., O’Brien, M., Brown, M., and Lim, E. (2015). Targeting the androgen receptor in breast cancer. Curr. Oncol. Rep. 17:4. doi: 10.1007/s11912-0140427-8

Chia, K. M., Liu, J., Francis, G. D., and Naderi, A. (2011). A feedback loop between androgen receptor and ERK signaling in estrogen receptor-negative breast cancer. Neoplasia 13, 154-166. doi: 10.1593/neo.101324

Daemen, A., and Manning, G. (2018). HER2 is not a cancer subtype but rather a pan-cancer event and is highly enriched in AR-driven breast tumors. Breast Cancer Res. 20:8. doi: 10.1186/s13058-018-0933-y

Dean, L. T., Gehlert, S., Neuhouser, M. L., Oh, A., Zanetti, K., Goodman, M., et al. (2018). Social factors matter in cancer risk and survivorship. Cancer Causes Control 29, 611-618. doi: 10.1007/s10552-018-1043-y 
DeSantis, C. E., Ma, J., Goding Sauer, A., Newman, L. A., and Jemal, A. (2017). Breast cancer statistics, 2017, racial disparity in mortality by state. CA Cancer J. Clin. 67, 439-448. doi: 10.3322/caac.21412

Epis, M. R., Giles, K. M., Barker, A., Kendrick, T. S., and Leedman, P. J. (2009). miR-331-3p regulates ERBB-2 expression and androgen receptor signaling in prostate cancer. J. Biol. Chem. 284, 24696-24704. doi: 10.1074/jbc.M109.030098

Fabbri, M., Paone, A., Calore, F., Galli, R., Gaudio, E., Santhanam, R., et al. (2012). MicroRNAs bind to Toll-like receptors to induce prometastatic inflammatory response. Proc. Natl. Acad. Sci. U.S.A. 109, E2110-E2116. doi: 10.1073/pnas. 1209414109

Fahlén, M., Zhang, H., Löfgren, L., Masironi, B., Von Schoultz, E., Von Schoultz, B. O., et al. (2018). Expression of progesterone and androgen receptors in the breast of premenopausal women, considering menstrual phase. Anticancer Res. 38, 1499-1510. doi: 10.21873/anticanres.12377

Farmer, P., Bonnefoi, H., Becette, V., Tubiana-Hulin, M., Fumoleau, P., Larsimont, D., et al. (2005). Identification of molecular apocrine breast tumours by microarray analysis. Oncogene 24, 4660-4671. doi: 10.1038/sj.onc.1208561

Feng, J., Li, L., Zhang, N., Liu, J., Zhang, L., Gao, H., et al. (2017). Androgen and AR contribute to breast cancer development and metastasis: an insight of mechanisms. Oncogene 36, 2775-2790. doi: 10.1038/onc.2016.432

Forman, J. J., Legesse-Miller, A., and Coller, H. A. (2008). A search for conserved sequences in coding regions reveals that the let-7 microRNA targets Dicer within its coding sequence. Proc. Natl. Acad. Sci. U.S.A. 105, 14879-14884. doi: 10.1073/pnas.0803230105

Foy, K. C., Fisher, J. L., Lustberg, M. B., Gray, D. M., DeGraffinreid, C. R., and Paskett, E. D. (2018). Disparities in breast cancer tumor characteristics, treatment, time to treatment, and survival probability among African American and white women. NPJ Breast Cancer 4:7. doi: 10.1038/s41523-018-0059-5

Gao, W., Bohl, C. E., and Dalton, J. T. (2005). Chemistry and structural biology of androgen receptor. Chem. Rev. 105, 3352-3370. doi: 10.1021/cr020456u

Giovannelli, P., Di Donato, M., Galasso, G., Di Zazzo, E., Bilancio, A., and Migliaccio, A. (2018). The androgen receptor in breast cancer. Front. Endocrinol. 9:492. doi: 10.3389/fendo.2018.00492

He, L., Du, Z., Xiong, X., Ma, H., Zhu, Z., Gao, H., et al. (2017). Targeting androgen receptor in treating HER2 positive breast cancer. Sci. Rep. 7:14584. doi: 10.1038/s41598-017-14607-2

Hickey, T. E., Irvine, C. M., Dvinge, H., Tarulli, G. A., Hanson, A. R., Ryan, N. K., et al. (2015). Expression of androgen receptor splice variants in clinical breast cancers. Oncotarget 6, 44728-44744. doi: 10.18632/oncotarget.6296

Hickey, T. E., Robinson, J. L. L., Carroll, J. S., and Tilley, W. D. (2012). Minireview: the androgen receptor in breast tissues: growth inhibitor, tumor suppressor, oncogene? Mol. Endocrinol. 26, 1252-1267. doi: 10.1210/me.2012-1107

Hu, D. G., Hickey, T. E., Irvine, C., Wijayakumara, D. D., Lu, L., Tilley, W. D., et al. (2014). identification of androgen receptor splice variant transcripts in breast cancer cell lines and human tissues. Horm. Cancer 5, 61-71. doi: 10.1007/ s12672-014-0171-4

Hu, R., Dawood, S., Holmes, M. D., Collins, L. C., Schnitt, S. J., Cole, K., et al. (2011). Androgen receptor expression and breast cancer survival in postmenopausal women. Clin. Cancer Res. 17, 1867-1874. doi: 10.1158/10780432.CCR-10-2021

Iorio, M. V., Ferracin, M., Liu, C.-G., Veronese, A., Spizzo, R., Sabbioni, S., et al. (2005). MicroRNA gene expression deregulation in human breast cancer. Cancer Res. 65, 7065-7070. doi: 10.1158/0008-5472.CAN-05-1783

Kim, J.-Y., Park, K., Lee, E., Jung, H. H., Ahn, J. S., Im, Y.-H., et al. (2017). The effect of androgen receptor expression on clinical characterization of metastatic breast cancer. Oncotarget 8, 8693-8706. doi: 10.18632/oncotarget.14414

Kim, S., Moon, B.-I., Lim, W., Park, S., Cho, M. S., and Sung, S. H. (2018). Feasibility of classification of triple negative breast cancer by immunohistochemical surrogate markers. Clin. Breast Cancer 18, e1123-e1132. doi: 10.1016/j.clbc.2018.03.012

Koboldt, D. C., Fulton, R. S., McLellan, M. D., Schmidt, H., Kalicki-Veizer, J., McMichael, J. F., et al. (2012). Comprehensive molecular portraits of human breast tumours. Nature 490, 61-70. doi: 10.1038/nature11412

Kozomara, A., and Griffiths-Jones, S. (2014). miRBase: annotating high confidence microRNAs using deep sequencing data. Nucleic Acids Res. 42, D68-D73. doi: 10.1093/nar/gkt1181

Kraby, M. R., Valla, M., Opdahl, S., Haugen, O. A., Sawicka, J. E., Engstrøm, M. J., et al. (2018). The prognostic value of androgen receptors in breast cancer subtypes. Breast Cancer Res. Treat. 172, 283-296. doi: 10.1007/s10549-0184904- $\mathrm{x}$

Labrie, F., Luu-The, V., Labrie, C., Bélanger, A., Simard, J., Lin, S.-X., et al. (2003). Endocrine and intracrine sources of androgens in women: inhibition of breast cancer and other roles of androgens and their precursor dehydroepiandrosterone. Endocr. Rev. 24, 152-182. doi: 10.1210/er.2001-0031

Lanzino, M., Sisci, D., Morelli, C., Garofalo, C., Catalano, S., Casaburi, I., et al. (2010). Inhibition of cyclin D1 expression by androgen receptor in breast cancer cells-identification of a novel androgen response element. Nucleic Acids Res. 38, 5351-5365. doi: 10.1093/nar/gkq278

Lehmann, B. D., Bauer, J. A., Chen, X., Sanders, M. E., Chakravarthy, A. B., Shyr, Y., et al. (2011). Identification of human triple-negative breast cancer subtypes and preclinical models for selection of targeted therapies. J. Clin. Invest. 121, 2750-2767. doi: 10.1172/JCI45014

Lehmann-Che, J., Hamy, A.-S., Porcher, R., Barritault, M., Bouhidel, F., Habuellelah, H., et al. (2013). Molecular apocrine breast cancers are aggressive estrogen receptor negative tumors overexpressing either HER2 or GCDFP15. Breast Cancer Res. 15:R37. doi: 10.1186/bcr3421

Lewis, B. P., Burge, C. B., and Bartel, D. P. (2005). Conserved seed pairing, often flanked by adenosines, indicates that thousands of human genes are microRNA targets. Cell 120, 15-20. doi: 10.1016/j.cell.2004.12.035

Lim, E., Ni, M., Cao, S., Hazra, A., Tamimi, R. M., and Brown, M. (2014). Importance of breast cancer subtype in the development of androgen-receptordirected therapy. Curr. Breast Cancer Rep. 6, 71-78. doi: 10.1007/s12609-0140140-5

Lin, H.-Y., Sun, M., Lin, C., Tang, H.-Y., London, D., Shih, A., et al. (2009). Androgen-induced human breast cancer cell proliferation is mediated by discrete mechanisms in estrogen receptor- $\alpha$-positive and -negative breast cancer cells. J. Steroid Biochem. Mol. Biol. 113, 182-188. doi: 10.1016/j.jsbmb. 2008.12.010

Lukong, K. E., Ogunbolude, Y., and Kamdem, J. P. (2017). Breast cancer in Africa: prevalence, treatment options, herbal medicines, and socioeconomic determinants. Breast Cancer Res. Treat. 166, 351-365. doi: 10.1007/s10549-0174408-0

Lytle, J. R., Yario, T. A., and Steitz, J. A. (2007). Target mRNAs are repressed as efficiently by microRNA-binding sites in the 5' UTR as in the 3' UTR. Proc. Natl. Acad. Sci. U.S.A. 104, 9667-9672. doi: 10.1073/pnas.0703820104

Lyu, S., Liu, H., Liu, X., Liu, S., Wang, Y., Yu, Q., et al. (2017). Interrelation of androgen receptor and miR-30a and miR-30a function in ER-, PR-, AR+ MDAMB-453 breast cancer cells. Oncol. Lett. 14, 4930-4936. doi: 10.3892/ol.2017. 6781

Lyu, S., Yu, Q., Ying, G., Wang, S., Wang, Y., Zhang, J., et al. (2014). Androgen receptor decreases CMYC and KRAS expression by upregulating let-7a expression in ER-, PR-, AR+ breast cancer. Int. J. Oncol. 44, 229-237. doi: 10.3892/ijo.2013.2151

Macedo, L. F., Guo, Z., Tilghman, S. L., Sabnis, G. J., Qiu, Y., and Brodie, A. (2006). Role of androgens on MCF-7 breast cancer cell growth and on the inhibitory effect of letrozole. Cancer Res. 66, 7775-7782. doi: 10.1158/0008-5472.CAN05-3984

McGhan, L. J., McCullough, A. E., Protheroe, C. A., Dueck, A. C., Lee, J. J., Nunez-Nateras, R., et al. (2014). Androgen receptor-positive triple negative breast cancer: a unique breast cancer subtype. Ann. Surg. Oncol. 21, 361-367. doi: 10.1245/s10434-013-3260-7

McNamara, K. M., Yoda, T., Nurani, A. M., Shibahara, Y., Miki, Y., Wang, L., et al. (2014). Androgenic pathways in the progression of triple-negative breast carcinoma: a comparison between aggressive and non-aggressive subtypes. Breast Cancer Res. Treat. 145, 281-293. doi: 10.1007/s10549-014-2942-6

Melo, S. A., Sugimoto, H., O’Connell, J. T., Kato, N., Villanueva, A., Vidal, A., et al. (2014). Cancer exosomes perform cell-independent MicroRNA biogenesis and promote tumorigenesis. Cancer Cell 26, 707-721. doi: 10.1016/j.ccell.2014.09. 005

Miglioretti, D. L., Zhu, W., Kerlikowske, K., Sprague, B. L., Onega, T., Buist, D. S. M., et al. (2015). Breast tumor prognostic characteristics and biennial vs annual mammography, age, and menopausal status. JAMA Oncol. 1, 1069-1077. doi: 10.1001/jamaoncol.2015.3084

Naderi, A., and Hughes-Davies, L. (2008). A functionally significant cross-talk between androgen receptor and ErbB2 pathways in estrogen receptor negative breast cancer. Neoplasia 10, 542-548. doi: 10.1593/neo.08274 
Nadiminty, N., Tummala, R., Lou, W., Zhu, Y., Zhang, J., Chen, X., et al. (2012). MicroRNA let-7c suppresses androgen receptor expression and activity via regulation of Myc expression in prostate cancer cells. J. Biol. Chem. 287, 1527-1537. doi: 10.1074/jbc.M111.278705

Nakano, K., Miki, Y., Hata, S., Ebata, A., Takagi, K., McNamara, K. M., et al. (2013). Identification of androgen-responsive microRNAs and androgen-related genes in breast cancer. Anticancer Res. 33, 4811-4819.

Nattenmüller, C. J., Kriegsmann, M., Sookthai, D., Fortner, R. T., Steffen, A., Walter, B., et al. (2018). Obesity as risk factor for subtypes of breast cancer: results from a prospective cohort study. BMC Cancer 18:616. doi: 10.1186/ s12885-018-4548-6

Ni, M., Chen, Y., Lim, E., Wimberly, H., Bailey, S. T., Imai, Y., et al. (2011). Targeting androgen receptor in estrogen receptor-negative breast cancer. Cancer Cell 20, 119-131. doi: 10.1016/j.ccr.2011.05.026

Park, S., Koh, E., Koo, J. S., Kim, S. I., Park, B.-W., and Kim, K.-S. (2017). Lack of both androgen receptor and forkhead box A1 (FOXA1) expression is a poor prognostic factor in estrogen receptor-positive breast cancers. Oncotarget 8 , 82940-82955. doi: 10.18632/oncotarget.20937

Parker, J. S., Mullins, M., Cheang, M. C. U., Leung, S., Voduc, D., Vickery, T., et al. (2009). Supervised risk predictor of breast cancer based on intrinsic subtypes. J. Clin. Oncol. 27, 1160-1167. doi: 10.1200/JCO.2008.18.1370

Perou, C. M., Sørlie, T., Eisen, M. B., van de Rijn, M., Jeffrey, S. S., Rees, C. A., et al. (2000). Molecular portraits of human breast tumours. Nature 406, 747-752. doi: 10.1038/35021093

Peters, A. A., Buchanan, G., Ricciardelli, C., Bianco-Miotto, T., Centenera, M. M., Harris, J. M., et al. (2009). Androgen receptor inhibits estrogen receptoractivity and is prognostic in breast cancer. Cancer Res. 69, 6131-6140. doi: 10.1158/0008-5472.CAN-09-0452

Rangel, N., Fortunati, N., Osella-Abate, S., Annaratone, L., Isella, C., Catalano, M. G., et al. (2018a). FOXA1 and AR in invasive breast cancer: new findings on their co-expression and impact on prognosis in ER-positive patients. $B M C$ Cancer 18:703. doi: 10.1186/s12885-018-4624-y

Rangel, N., Rondon-Lagos, M., Annaratone, L., Osella-Abate, S., Metovic, J., Mano, M. P., et al. (2018b). The role of the AR/ER ratio in ER-positive breast cancer patients. Endocr. Relat. Cancer 25, 163-172. doi: 10.1530/ERC-17-0417

Ribas, J., Ni, X., Haffner, M., Wentzel, E. A., Salmasi, A. H., Chowdhury, W. H., et al. (2009). miR-21: an androgen receptor-regulated MicroRNA that promotes hormone-dependent and hormone-independent prostate cancer growth. Cancer Res. 69, 7165-7169. doi: 10.1158/0008-5472.CAN-09-1448

Ricciardelli, C., Bianco-Miotto, T., Jindal, S., Butler, L. M., Leung, S., McNeil, C. M., et al. (2018). The magnitude of androgen receptor positivity in breast cancer is critical for reliable prediction of disease outcome. Clin. Cancer Res. 24, 2328-2341. doi: 10.1158/1078-0432.CCR-17-1199

Robinson, J. L. L., MacArthur, S., Ross-Innes, C. S., Tilley, W. D., Neal, D. E., Mills, I. G., et al. (2011). Androgen receptor driven transcription in molecular apocrine breast cancer is mediated by FoxA1. EMBO J. 30, 3019-3027. doi: 10.1038/emboj.2011.216

Ross-Innes, C. S., Stark, R., Teschendorff, A. E., Holmes, K. A., Ali, H. R., Dunning, M. J., et al. (2012). Differential oestrogen receptor binding is associated with clinical outcome in breast cancer. Nature 481, 389-393. doi: 10.1038/ nature 10730

Rothman, M. S., Carlson, N. E., Xu, M., Wang, C., Swerdloff, R., Lee, P., et al. (2011). Reexamination of testosterone, dihydrotestosterone, estradiol and estrone levels across the menstrual cycle and in postmenopausal women measured by liquid chromatography-tandem mass spectrometry. Steroids 76 , 177-182. doi: 10.1016/j.steroids.2010.10.010

Schrijver, W. A. M. E., Schuurman, K., van Rossum, A., Consortium, D. D. B. C. M., Peeters, T., Ter Hoeve, N., et al. (2017). Loss of steroid hormone receptors is common in malignant pleural and peritoneal effusions of breast cancer patients treated with endocrine therapy. Oncotarget 8, 55550-55561. doi: 10.18632/ oncotarget.15548

Severson, T. M., Kim, Y., Joosten, S. E. P., Schuurman, K., van der Groep, P., Moelans, C. B., et al. (2018). Characterizing steroid hormone receptor chromatin binding landscapes in male and female breast cancer. Nat. Commun. 9:482. doi: 10.1038/s41467-018-02856-2

Shi, X.-B., Xue, L., Yang, J., Ma, A.-H., Zhao, J., Xu, M., et al. (2007). An androgen-regulated miRNA suppresses Bak1 expression and induces androgenindependent growth of prostate cancer cells. Proc. Natl. Acad. Sci. U.S.A. 104, 19983-19988. doi: 10.1073/pnas.0706641104

Shi, Y., Yang, F., Sun, Z., Zhang, W., Gu, J., and Guan, X. (2017). Differential microRNA expression is associated with androgen receptor expression in breast cancer. Mol. Med. Rep. 15, 29-36. doi: 10.3892/mmr.2016.6019

Siegel, R. L., Miller, K. D., and Jemal, A. (2018). Cancer statistics, 2018. CA Cancer J. Clin. 68, 7-30. doi: 10.3322/caac. 21442

Tabung, F. K., Steck, S. E., Liese, A. D., Zhang, J., Ma, Y., Caan, B., et al. (2016). Association between dietary inflammatory potential and breast cancer incidence and death: results from the Women's Health Initiative. Br. J. Cancer 114, 1277-1285. doi: 10.1038/bjc.2016.98

Takagi, K., Miki, Y., Ishida, T., Sasano, H., and Suzuki, T. (2018). The interplay of endocrine therapy, steroid pathways and therapeutic resistance: importance of androgen in breast carcinoma. Mol. Cell. Endocrinol. 466, 31-37. doi: 10.1016/ j.mce.2017.09.011

Takagi, K., Miki, Y., Nagasaki, S., Hirakawa, H., Onodera, Y., Akahira, J., et al. (2010). Increased intratumoral androgens in human breast carcinoma following aromatase inhibitor exemestane treatment. Endocr. Relat. Cancer 17, 415-430. doi: 10.1677/ERC-09-0257

Vasudevan, S., Tong, Y., and Steitz, J. A. (2007). Switching from repression to activation: microRNAs can up-regulate translation. Science 318, 1931-1934. doi: 10.1126/science.1149460

Vera-Badillo, F. E., Templeton, A. J., de Gouveia, P., Diaz-Padilla, I., Bedard, P. L., Al-Mubarak, M., et al. (2014). Androgen receptor expression and outcomes in early breast cancer: a systematic review and meta-analysis. JNCI J. Natl. Cancer Inst. 106, djt319-djt319. doi: 10.1093/jnci/djt319

Wang, C., Pan, B., Zhu, H., Zhou, Y., Mao, F., Lin, Y., et al. (2016). Prognostic value of androgen receptor in triple negative breast cancer: a meta-analysis. Oncotarget 7, 46482-46491. doi: 10.18632/oncotarget. 10208

Yang, F., Shen, Y., Zhang, W., Jin, J., Huang, D., Fang, H., et al. (2018). An androgen receptor negatively induced long non-coding RNA ARNILA binding to miR-204 promotes the invasion and metastasis of triple-negative breast cancer. Cell Death Differ. 25, 2209-2220. doi: 10.1038/s41418-0180123-6

Zhang, W., Liu, X., Liu, S., Qin, Y., Tian, X., Niu, F., et al. (2018). Androgen receptor/let-7a signaling regulates breast tumor-initiating cells. Oncotarget 9 , 3690-3703. doi: 10.18632/oncotarget.23196

Conflict of Interest Statement: The authors declare that the research was conducted in the absence of any commercial or financial relationships that could be construed as a potential conflict of interest.

Copyright (c) 2019 Bandini and Fanini. This is an open-access article distributed under the terms of the Creative Commons Attribution License (CC BY). The use, distribution or reproduction in other forums is permitted, provided the original author(s) and the copyright owner(s) are credited and that the original publication in this journal is cited, in accordance with accepted academic practice. No use, distribution or reproduction is permitted which does not comply with these terms. 